\title{
Heterosis and nuclear DNA content in maize
}

\author{
D. P. BIRADAR AND A. LANE RAYBURN \\ Department of Agronomy, 320 Plant and Animal Biotechnology Laboratory, University of Illinois, Urbana, IL 61801,
} U.S.A.

\begin{abstract}
Twenty-five $F_{1}$ maize hybrids were analysed with respect to their nuclear DNA content. Twelve of the hybrids have been reported previously to have a low heterotic response while 13 have a high heterotic response. The nuclear DNA content of each $F_{1}$ hybrid was compared with the midpoint DNA amount of its respective parents. In nine of the hybrids with the low heterotic response, the observed nuclear DNA amount exceeded the expected DNA amount by approximately 5 per cent. In 12 of the 13 hybrids that had a high heterotic response, the observed nuclear DNA amount was not significantly different from the expected DNA amount. These results demonstrate an association between heterotic response and nuclear DNA content inheritance in $F_{1}$ hybrids of maize.
\end{abstract}

Keywords: flow cytometry, genome size, hybrid vigour, nuclear organization.

\section{Introduction}

Since its inception in 1909, the pure line hybrid concept developed by Shull has been extensively used in maize breeding (Shull, 1909). This breeding concept allows one to take advantage of the immense amount of heterosis that occurs in maize. Heterosis was defined by Shull (1911) as 'the superiority of heterozygous genotypes with respect to one or more characters in comparison with the corresponding homozygotes. Heterosis is the phenotypic result of gene interaction in heterozygotes and is thus confined (at least in maximal amount) to that state' (taken from Reiger et al., 1976). The degree of heterosis one observes appears to increase as the genetic similarities between the two parents decrease (East, 1936). Although heterosis is observed in maize as well as in a variety of other organisms, the specific basis of heterosis is not known.

Heterosis appears to be a complex phenomenon which is an important component of cross-fertilizing species (Elliot, 1958). Due to the complexity of heterosis, it may be difficult to ever determine the exact nature of heterosis. Pontecorvo (1955) stated '... the first steps for an understanding of heterosis... should be towards a better understanding of gene structure and action. Only then would the approach at the higher level of population genetics become illuminating'. While this statement appears restricted to studies of single (or quantitative) genes, implied in the statement is the importance of genome organization and its role in heterosis. Bennett (1984) reviewed quite extensively the role of nuclear architecture in $F_{1}$ hybrids of plants. Nuclear organization, therefore, should not be ignored when studying heterosis.

Rayburn et al. (1993) determined the nuclear DNA content of several inbred lines and $\mathrm{F}_{1}$ hybrids in maize. They observed two distinct patterns of inheritance. In the first pattern, the nuclear DNA content of the hybrid is equivalent to the parental midpoint DNA amount. In the second pattern, the nuclear DNA amount of the hybrid was significantly higher than the parental midpoint. Included in the maize hybrids examined were hybrids that demonstrated high heterosis as well as hybrids that demonstrated low heterosis.

Observing two types of inheritance patterns in these hybrids leads one to speculate the influence of heterosis on these patterns. The objective of this research was to determine if the degree of heterosis observed in a hybrid may have an influence on the inheritance pattern in specific $F_{1}$ hybrids.

\section{Materials and methods}

Seventeen $F_{1}$ hybrids were selected for analysis on the basis of their heterotic response (Table 1). Nine of the hybrids were defined by Zanoni \& Dudley (1989) as having a heterotic response between 5.6 and $6.1 \mathrm{Mg}$ $\mathrm{ha}^{-1}$. The remaining eight hybrids had heterotic responses ranging from 3.3 to $3.9 \mathrm{Mg} \mathrm{ha}^{-1}$. In order to determine the expected nuclear DNA content, the 
nuclear DNA content of the parental lines was needed. The genome size of nine of the 14 parental lines had previously been determined by Rayburn et al. (1993). The remaining five inbred lines were examined in this study (Table 1). All of the lines examined in this study, as well as in Rayburn et al. (1993), were grown on the agronomy south farm at the University of Illinois, Urbana, IL, selfed and the specific $F_{1}$ hybrids obtained in the summer of 1990 . At least three crosses were made per hybrid.

The nuclear DNA content of the five inbred lines and 17 hybrids was determined according to Rayburn et al. (1989). Nuclei were isolated from individual stems of 2-week-old seedlings, stained with DAPI (4'6-diamidino-2-phenylindole) and analysed on an EPICS 751 flow cytometer-cell sorter. Five thousand nuclei were examined per nuclei isolation. The 10 nuclear isolations analysed for each inbred line or hybrid represented 10 individual plants. Each day, W22 was used as an external standard, set at channel 100 and defined as having 100 arbitrary units (A.U.).

In addition to the 17 hybrids examined in this study, eight hybrids observed by Rayburn et al. (1993) were also statistically analysed. The hybrids $\mathrm{H} 100 \times \mathrm{H} 102$, $\mathrm{B} 84 \times \mathrm{Mo} 17, \mathrm{H} 100 \times \mathrm{Pa} 91$, and $\mathrm{Pa} 91 \times \mathrm{H} 102$ all had high heterotic responses ranging from 5.6 to $7.3 \mathrm{Mg}$ $\mathrm{ha}^{-1}$. The hybrids B73 $\times \mathrm{B} 84, \mathrm{H} 95 \times \mathrm{Va} 26$, Mo17 $\times$ H102, and $\mathrm{H} 100 \times$ N7A all had relatively low heterotic responses ranging from 2.0 to $3.3 \mathrm{Mg} \mathrm{ha}^{-1}$. The expected $F_{1}$ nuclear DNA content for all hybrids was calculated as $(\mathrm{P} 1+\mathrm{P} 2) / 2$. $t$-tests between the expected and observed genome sizes were run for each hybrid.

\section{Results}

The five inbred lines were observed to have genome sizes ranging from 11.1 to 10.6 picograms (pg) per $4 \mathrm{C}$ nucleus (Table 1). These nuclear DNA contents are well within the range already observed for mid-western US inbred maize. The nuclear DNA content of the $F_{1}$ hybrids ranged from 11.0 to 10.0 pg per $4 \mathrm{C}$ nucleus (Table 1). Again, this range of nuclear DNA contents was well within the norm for $F_{1}$ maize hybrids examined previously. In all of the hybrids examined, all 10 plants examined were observed to cluster around their respective genome size.

Thirteen hybrids were examined which exhibited a high heterotic response. In 12 of the 13 hybrids, the observed nuclear DNA amount was not significantly different from the expected DNA content (Table 2). Only in the hybrid $\mathrm{H} 100 \times \mathrm{H} 102$ was a significant deviation from the expected DNA amount found. In this hybrid, the nuclear DNA content was higher than
Table 1 Genome size of the inbred lines and $F_{1}$ hybrids

\begin{tabular}{|c|c|c|c|}
\hline Line & $\begin{array}{l}\text { Mean genome } \\
\text { size }(A . U)^{*}\end{array}$ & s.d. & $\mathrm{DNA}(\mathrm{pg}) \dagger$ \\
\hline \multicolumn{4}{|l|}{ Inbreds } \\
\hline B57 & 99.3 & 1.1 & 10.6 \\
\hline B73 & 90.8 & 3.6 & 9.7 \\
\hline B75 & 103.7 & 1.4 & 11.1 \\
\hline B77 & 101.0 & 0.9 & 10.8 \\
\hline B79 & 98.7 & 1.8 & 10.6 \\
\hline B84ł & 92.7 & 2.6 & 9.9 \\
\hline H95 & 95.4 & 1.3 & 10.2 \\
\hline H100‡ & 94.4 & 1.2 & 10.1 \\
\hline H102‡ & 95.6 & 3.8 & 10.2 \\
\hline Mo17‡ & 88.8 & 4.0 & 9.5 \\
\hline N7A $\ddagger$ & 92.9 & 3.2 & 9.9 \\
\hline N152 & 100.4 & 1.3 & 10.7 \\
\hline Pa91‡ & 99.2 & 3.6 & 10.6 \\
\hline Va26 & 96.7 & 2.8 & 10.3 \\
\hline \multicolumn{4}{|l|}{$F_{1}$ hybrids } \\
\hline $\mathrm{B} 75 \times \mathrm{Va} 26$ & 102.8 & 0.8 & 11.0 \\
\hline B $79 \times$ H95 & 102.1 & 0.6 & 10.9 \\
\hline B75 × H95 & 101.2 & 0.6 & 10.8 \\
\hline $\mathrm{Pa} 91 \times \mathrm{H} 95$ & 100.5 & 0.9 & 10.8 \\
\hline B57 × H95 & 100.5 & 0.6 & 10.8 \\
\hline $\mathrm{B} 84 \times \mathrm{N} 7 \mathrm{~A}$ & 100.1 & 1.4 & 10.7 \\
\hline B79 × H95 & 99.9 & 0.6 & 10.7 \\
\hline $\mathrm{N} 152 \times \mathrm{Va} 26$ & 98.6 & 0.3 & 10.5 \\
\hline $\mathrm{H} 100 \times \mathrm{Va} 26$ & 97.5 & 0.7 & 10.4 \\
\hline $\mathrm{H} 100 \times \mathrm{B} 77$ & 97.5 & 0.5 & 10.4 \\
\hline $\mathrm{B} 73 \times \mathrm{N} 7 \mathrm{~A}$ & 97.5 & 0.4 & 10.4 \\
\hline $\mathrm{H} 102 \times \mathrm{N} 152$ & 97.1 & 1.4 & 10.4 \\
\hline $\mathrm{N} 7 \mathrm{~A} \times \mathrm{H} 102$ & 96.9 & 1.1 & 10.4 \\
\hline B84 × Pa91 & 96.0 & 1.7 & 10.3 \\
\hline $\mathrm{B} 73 \times \mathrm{H} 102$ & 95.5 & 1.2 & 10.2 \\
\hline $\mathrm{B} 73 \times \mathrm{Pa} 91$ & 94.4 & 1.2 & 10.1 \\
\hline $\mathrm{H} 100 \times \mathrm{Mo} 17$ & 93.1 & 0.6 & 10.0 \\
\hline
\end{tabular}

*Based on W22 $=100$ Arbitrary Units. $\dagger$ Based on $W 22=10.7 \mathrm{pg} / 4 \mathrm{C}$ nucleus. $\ddagger$ Data taken from Rayburn et al. (1993).

expected. In the 12 hybrids which showed no significant difference from the expected, seven were observed to have a nuclear DNA content numerically higher than the expected, three hybrids were observed to have nuclear DNA contents numerically lower than expected and two hybrids had nuclear DNA contents equivalent to the expected value.

In the 12 hybrids with low heterotic response, a different trend was observed (Table 3 ). In nine of the 12 hybrids, the observed nuclear DNA content deviated significantly from the expected $F_{1}$ DNA amount. In all nine hybrids, the nuclear DNA amount was higher than expected. In the remaining three hybrids, the observed DNA amount was also numeri- 
Table 2 Statistical analyses of genome sizes in high heterotic response $F_{1}$ hybrids

\begin{tabular}{lllll}
\hline Hybrid & $\begin{array}{l}\text { Heterotic } \\
\text { response* }\end{array}$ & $\begin{array}{l}\text { Expected nuclear } \\
\text { DNA content } \dagger\end{array}$ & $\begin{array}{l}\text { Observed nuclear } \\
\text { DNA content }\end{array}$ & $P>t \neq$ \\
\hline H100 $\times$ H102§ & 7.3 & 95.0 & 100.2 & $* *$ \\
B84 $\times$ Mo17§ & 6.7 & 90.8 & 92.0 & NS \\
H100 $\times$ Pa91§ & 6.2 & 96.8 & 98.2 & NS \\
H100 $\times$ Mo17 & 6.1 & 91.6 & 93.1 & NS \\
N7A $\times$ H102 & 6.0 & 94.3 & 96.7 & NS \\
H102 $\times$ N152 & 5.9 & 98.0 & 97.1 & NS \\
B73 $\times$ H102 & 5.9 & 93.2 & 95.5 & NS \\
Pa91 $\times$ H102 & 5.9 & 97.4 & 98.4 & NS \\
B84 $\times$ Pa91 & 5.8 & 96.0 & 96.0 & NS \\
H100 $\times$ Va26 & 5.8 & 95.5 & 97.5 & NS \\
H100 $\times$ B77 & 5.7 & 97.7 & 97.5 & NS \\
B73 $\times$ Pa91 & 5.7 & 95.0 & 94.4 & NS \\
N152 $\times$ Va26 & 5.6 & 98.5 & 98.5 & \\
\hline
\end{tabular}

${ }^{*} \mathrm{Mg} \mathrm{ha}^{-1}$ for yield heterosis taken from Zanoni \& Dudley (1989).

$\dagger(\mathbf{P} 1+\mathbf{P} 2) / 2$.

$\ddagger \mathrm{NS}=$ not significant at 0.05 level, ${ }^{* *}=$ significant at 0.05 level.

$\S$ Data taken from Rayburn et al. (1993).

Table 3 Statistical analyses of genome sizes in low heterotic response $F_{1}$ hybrids

\begin{tabular}{llccl}
\hline Hybrid & $\begin{array}{l}\text { Heterotic } \\
\text { response* }\end{array}$ & $\begin{array}{l}\text { Expected nuclear } \\
\text { DNA content } \dagger\end{array}$ & $\begin{array}{l}\text { Observed nuclear } \\
\text { DNA content }\end{array}$ & $P>t \ddagger$ \\
\hline B73 $\times$ B84 & $2.0 \S$ & 91.8 & 94.4 & NS \\
H95 $\times$ Va26 & $2.8 \S$ & 96.1 & 99.4 & $* *$ \\
Mo17 $\times$ H102 & $3.2 \S$ & 92.2 & 97.3 & $* *$ \\
B84 $\times$ N7A & 3.3 & 92.8 & 100.1 & $* *$ \\
H100 $\times$ N7A & $3.3 \S$ & 93.7 & 98.7 & $* *$ \\
B73 N7A & 3.4 & 91.9 & 97.5 & $* *$ \\
B57 $\times$ H95 & 3.4 & 97.3 & 100.5 & $* *$ \\
B75 $\times$ Va26 & 3.4 & 100.2 & 102.8 & NS \\
B79 $\times$ H95 & 3.5 & 97.1 & 99.9 & $* *$ \\
Pa91 $\times$ H95 & 3.8 & 97.3 & 102.1 & $* *$ \\
N7A $\times$ B57 & 3.9 & 96.1 & 100.5 & $* *$ \\
B75 $\times$ H95 & 3.9 & 99.5 & 101.2 & NS \\
\hline
\end{tabular}

${ }^{*} \mathrm{Mg} \mathrm{ha}^{-1}$ for yield heterosis taken from Zanoni \& Dudley, (1989).

$\dagger(\mathbf{P} 1+\mathrm{P} 2) / 2$.

$\ddagger \mathrm{NS}=$ not significant at 0.05 level, ${ }^{* *}=$ significant at 0.05 level.

$\S$ Data taken from Rayburn et al. (1993).

cally higher than the expected although not statistically significant.

\section{Discussion}

The five inbred lines examined represented various unrelated sources of germplasm and were designated 'o' for other (Zanoni \& Dudley, 1989). The lines are not closely related to either the Stiff Stalk Synthetics $(\mathrm{S})$ or the Lancaster $(\mathrm{L})$ lines. The total nuclear DNA amount of these lines on the average were higher than those of the L lines observed by Rayburn et al. (1993). The DNA amounts were, however, well within the nuclear DNA amounts observed within the maize inbred lines examined by Rayburn et al. (1985).

In $F_{1}$ hybrids with a high heterotic response, the nuclear DNA amount was approximately as predicted. In only one case did the nuclear DNA amount differ 
significantly from the expected. This hybrid was an $\mathrm{S} \times \mathrm{L}$ hybrid. Other $\mathrm{S} \times \mathrm{L}$ hybrids did not demonstrate this variation from the expected indicating that ancestral pedigree was not responsible for the deviation. The only communality between $\mathrm{F}_{1}$ hybrids with a high heterotic response was that they were all crosses between somewhat unrelated lines $(\mathrm{S} \times \mathrm{L}, \mathrm{S} \times \mathrm{O}$, $\mathrm{L} \times \mathrm{O})$.

One $F_{1}$ hybrid with a high heterotic response was not the result of one of the crosses described above but was in fact an $\mathrm{L} \times \mathrm{L}$ cross. The nuclear DNA content of this hybrid did not differ from the expected midparent. The parents of this cross were $\mathrm{H} 100$ and $\mathrm{Pa} 91$. Interestingly, $\mathrm{Pa} 91$ has a somewhat unique pedigree when compared with the other $L$ lines observed in this study. Although the cross is an $\mathrm{L} \times \mathrm{L}, \mathrm{Pa} 91$ is more distantly related to the other $\mathrm{L}$ lines. Therefore, the hybrids with high heterotic responses, which are the result of crossing two parents of somewhat unrelated backgrounds, appear to have a stable inheritance of nuclear DNA.

When one analyses the hybrids with low heterotic responses, a quite different phenomenon is observed. In nine of the 12 hybrids, the nuclear DNA content of the $F_{1}$ hybrid deviated significantly from the predicted DNA amount. Six of these hybrids were $\mathrm{S} \times \mathrm{S}$ or $\mathrm{L} \times \mathrm{L}$ crosses, indicating that the genomes which were being combined were similar. The remaining three hybrids with the higher than expected DNA amount were $\mathrm{L} \times \mathrm{O}$ or $\mathrm{S} \times \mathrm{O}$. The low heterotic response observed in these hybrids suggests that the $\mathrm{O}$ parents in each of these crosses were in some way related to the respective $\mathrm{S}$ and $\mathrm{L}$ parent.

Of the three hybrids which did not demonstrate a significant difference from the expected genome size, two were $\mathrm{O} \times \mathrm{L}$ crosses. In both cases, the $\mathrm{O}$ parent was B75. The behavior of these hybrids with respect to inheritance of genome size suggests that B75 is not as closely related to the $\mathrm{L}$ lines as are B57 and B79. Maize lines with closely related genomes appear to produce hybrids which contain significantly higher than the expected nuclear DNA content.

Maize is a cross-fertilizing crop species. The effects of self-fertilization in a cross-fertile species include reduction in height and yield, loss of vigour and appearances of abnormalities due to genetic load. While such events are deleterious in the majority of species, maize tolerates self-fertilization better than any other major cross-fertilized crop (Elliot, 1958). Maize has been described as an atypical cross-fertilization crop species due in part to its long history of domestication by man and its inability to survive without man's intervention. The fact that maize in not a typical cross-fertilized crop species requires caution when extrapolating charac- teristics of maize associated with cross-fertilization to other cross-fertile crop or native species (Elliot, 1958).

Due to the ability of maize to tolerate considerable inbreeding, man has induced differentiation into maize which has resulted in the formation of a large number of distinct races. In addition, many pure line inbred lines of very distinct genetic background have been developed. The use of these pure breeding lines has become an important component of maize agriculture. This is due in part to the large amount of heterosis observed in $F_{1}$ hybrids of maize. Determining how combining specific pure line hybrids affects the genomic organization of the resulting hybrid and the performance of such hybrids will provide initial clues as to the association between genome organization and heterosis.

Narayan (1988) hypothesized that interspecific hybrids showed genomic imbalance which may be associated with gain or loss in nuclear DNA amount. The theory presented indicated that the more closely related the genomes, the more stable the genomic organization would be. In maize, the opposite was observed. The hybrids which were the result of combining similar or closely related genomes resulted in amplifications of nuclear DNA sequences. When genomes which were more distantly related were combined, no deviations from the expected nuclear DNA amounts were observed. While four exceptions to these observations were noted, they all appeared to have special circumstances that could in part explain their nuclear DNA inheritance. Apparently, the maize plant has the ability to more precisely organize unrelated genomes without modification than closely related genomes in the hybrid nucleus. These results are contradictory to what one might have expected. However, maize, being a normal cross-fertilizing species, may have developed such a mechanism to deter inbreeding. The best performing, most stable hybrids would be those with the most stable genome organization as reflected by normal DNA inheritance.

In conclusion, nuclear genome organization in hybrid maize as indicated by nuclear DNA content inheritance is influenced by the relatedness of the parental lines. Those hybrids whose parents are somewhat distantly related are able to organize the DNA within the nucleus with no deletion or amplification of DNA sequences. Those hybrids whose parents are more closely related appear to have difficulties in organizing the two parental genomes and DNA amplification occurs. Associated with the normal inheritance of nuclear DNA content is a high heterotic response. DNA amplification is associated with a low heterotic response. Whether the DNA amplification is the cause of the low heterotic response or whether the low 
heterotic response causes the DNA amplification was not determined. Regardless of the cause, a relationship between heterotic response and nuclear genome organization is observed in maize.

\section{References}

BENNETT, M. D. 1984. Nuclear architecture and its manipulation. In: Gustafson, J. P. (ed.) Gene Manipulation in Plant Improvement. Plenum Press, New York, pp. 469-502.

EAST, E. M. 1936. Heterosis. Genetics, 21, 375-397.

ELLIOTT, F. C. 1958. Plant Breeding and Cytogenetics. McGrawHill, New York.

NARAYAN, R. K. J. 1988. Evolutionary significance of DNA variation in plants. Evol. Trends Plants, 2, 121-130.

PONTECORVO, G. 1955. Gene structure and action in relation to heterosis. Proc. Roy. Soc. (London), 144 B, 171-177.
RAYBURN, A. L., PRICE, H. J., SMITH, J. D. AND GOLD, J. R. 1985. C-band heterochromatin and DNA content in Zea mays (L.). Am. J. Bot., 72, 1610-1617.

RAYBURN, A. L., AUGER, J. A., BENZINGER, E. A. AND HEPBURN, A. G. 1989. Detection of intraspecific DNA content variation in Zea mays L. by flow cytometry. J. Exp. Bot., 40, 1179-1183.

RAYBURN, A. L., BIRADAR, D. P., BULLOCK, D. G. AND McMURPHY, L. M. 1993. Nuclear DNA content in $F_{1}$ hybrids of maize. Heredity, 70, 294-300.

REIGER, R., MICHAELIS, A. AND GREEN, M. M. 1976. Glossary of Genetics and Cytogenetics. Springer-Verlag, Berlin.

SHULL, G. H. 1909. A pure line method in corn breeding. Am. Breeders Assoc. Repts, 5, 51-59.

SHULL, G. H. 1911. Hybridization methods in corn breeding. Am. Breeders Assoc. Repts, 6, 63-72.

ZANONI, U. AND DUDLEY, J. W. 1989. Comparison of different methods of identifying inbreds useful for improving elite maize hybrids. Crop Sci., 29, 577-582. 